\title{
Aspectos da oralidade em Niketche, uma história de poligamia, de Paulina Chiziane
}

\section{Aspects of ORALity in Niketche, a history of POlygamy, by Paulina Chiziane}

Jéssica Fabrícia da Silval

DOI: 10.11606/issn.1981-7169.crioula.2017.134823

RESUMO: Este artigo pretende observar como a oralidade compõe o processo de escrita da moçambicana Paulina Chiziane em seu romance Niketche: uma história de poligamia, pois, no que tange aos processos de escritas utilizados neste livro, há uma oralidade pulsante que coordena toda a estrutura narrativa.

ABSTRACT: This article intends to observe how orality composes the writing process of the Mozambican writer Paulina Chiziane in her novel Niketche: uma história de poligamia, since, as far as the writing processes used in this book are concerned, there is a pulsating orality that coordinates the entire narrative structure.

PALAVRAS-CHAVE: Oralidade; Paulina Chiziane; Romance Moçambicano; Literaturas Africanas.

KEYWORDS: Orality; Paulina Chiziane; Mozambican Novel; African Literatures.

1 Licenciatura em Letras pela Faculdade de Ciências e Letras de Araraquara - UNESP. Mestranda em Teoria e História Literária pelo Instituto de Estudos da Linguagem - UNICAMP. Estuda "As (des)semelhanças das mulheres moçambicanas em Niketche, uma história de poligamia, de Paulina Chiziane". 
escritora moçambicana Paulina Chiziane foi a primei- ra mulher a publicar um romance, Balada de Amor ao Vento, em seu país, em 1990. Chiziane teve que resistir às dificuldades em se tornar escritora em uma sociedade que não possibilitava a ascensão socioeconômica da mulher e enfrentou a Associação dos Escritores de Moçambique. Tais contratempos não desapareceram com a publicação do livro, acabando por aumentarem, como a própria autora explicita em uma entrevista ao jornal Expresso:

O meu primeiro livro levantou muitas dúvidas: primeiro uma mulher que escreve, depois que fuma, depois que fala de amor... Não deve ser flor que se cheire. Tentavam afastar-me da sociedade, ainda continuo a ser vista como uma aventureira, como uma pessoa que não tem âncora no meio social. (MOREIRA, 1999, p.1).

Assim, percebe-se que a tarefa de escrever para ela sempre foi um caminho árduo, pois "[...] nas condições da actual sociedade, se a mulher pretende um reconhecimento igual ao do seu parceiro masculino deve trabalhar duas ou três vezes mais" (CHIZIANE, 2012, p.203).

A pesquisadora Inocência Mata, em seu artigo "Mulheres de África no espaço da escrita: a inscrição da mulher na sua diferença" (2007), explicita a importância da escritura feminina africana. Segundo a estudiosa, é possível compreender as diferenças sociais, culturais, históricas e econômicas das - e entre as - mulheres na sociedade por meio das imagens construídas pelas escritoras em seus livros. Desse modo, Matta se 
distancia da proposição feita por Gayatri Chakravorty Spivak, que considera improvável o papel da resistência a partir de uma escrita feminina. Segundo Spivak "o subalterno como um sujeito feminino não pode ser ouvido ou lido" (2014, p.63).

A partir dessa percepção do papel da escritura feminina, buscar-se-á, neste artigo, compreender como a questão da oralidade se funde ao fazer literário de Paulina Chiziane em seu livro Niketche, uma história de poligamia, publicado em 2002, já que "[...] pela escrita - que compõe esse 'documento literário' - pode-se chegar a essa 'história' de vozes silenciadas, pois é também a escrita representação do indizível" (MATTA, 2007, p.423).

\section{NIKETCHE, UMA HISTÓRIA DE POLIGAMIA \& ORALIDADE}

A professora especialista em literaturas africanas, Ana Mafalda Leite, em seu estudo Oralidades \& escritas pós-coloniais (2013), faz um longo estudo de como esse fenômeno é compreendido na literatura escrita e suas consequências no sistema linguístico como um todo. Para ela a língua deve ser pensada e analisada nos textos literários africanos, pois ficam evidentes neles os processos de identificação dos autores: "[...] a relação com o corpo linguístico começa por manifestar-se pelas diferentes 'falas' com que os escritores africanos se assenhorearam da 'língua'” (LEITE, 2013, p.19-20). Dessa forma, a língua passa por uma espécie de africanização em diversos níveis, subvertendo um dos instrumentos de poder mais importantes do colonizador. 
Entretanto, um fato interessante afirmado pela estudiosa é o de a oralidade ser "[...] resultante de condições materiais e históricas e não uma resultante da 'natureza africana' [...]" (LEITE, 2013, p.20). Esse fato também é observado pelos pesquisadores Rejane Vecchia da Rocha e Silva e Ubiratã Roberto Bueno de Souza (2015), no artigo "Literatura moçambicana e oralidade: uma postura crítica e uma fundamentação teórica". Eles explicitam que é errôneo admitir que exista, em todo território do continente africano, dada a sua grande extensão territorial, uma "tradição oral", já que não são todas as sociedades autóctones que presenciaram a oralidade como condição para se perpetuar o conhecimento adquirido. Hampatê Bá (2010), em seu artigo "A tradição viva", também explicita esse ponto ao ser cuidadoso em afirmar que seus estudos se baseiam nas sociedades africanas que se localizam em "[...] toda a região de savana ao sul do Saara [...]" (HAMPATÊ BÁ, 2010, p.182).

Em inúmeras entrevistas, Paulina Chiziane faz questão de (re)afirmar que as técnicas narrativas de suas obras são calcadas na oralidade, chamando a si mesma de "contadora de histórias":

O meu ponto de partida é a oralidade, e todos os meus trabalhos até hoje são baseados na tradição oral, daí que eu não gosto de dizer que fiz um romance, uma novela ou seja o que for. Eu conto uma história e ao contá-la acrescento um ponto. E ela pode ser grande ou pequena. Essa é a minha primeira receita. (MANJATE, 2004, p.2, grifos nossos). 
Destarte, nos livros da escritora moçambicana a escoIha pelo modo como serão narradas as histórias possui um elo fundamental com a temática apresentada nos textos, pois, como já dito, Chiziane busca evidenciar as práticas e os costumes da sociedade moçambicana. Logo, percebe-se a existência de cunho moralizante "[...] do acto narrativo, [...] essencialmente comunitário e social, característico da oratura" (LEITE, 2013, p.78). Todavia, deve-se ressaltar, ainda, que esse processo de moralização é deliberado.

Em Niketche, uma história de poligamia, o leitor depara-se com a história da narradora Rami, que se encontra insatisfeita em seu casamento com o comandante de polícia António Tomás, o Tony. Vivendo dentro de uma sociedade pautada pelos preceitos da religião católica, Rami respeita a posição de esposa da qual está imbuída, ou seja, realiza o papel de mulher muitas vezes submissa e oprimida dentro do casamento, relegando seus desejos em nome do marido. Entretanto, apesar dos sacrifícios da protagonista, Tony não se importa em honrar os votos matrimoniais, ausentando-se do lar e retornando poucas vezes. Assim, cansada de ser deixada de lado, a narradora-protagonista parte em busca de seu marido, indo em direção à casa de Julieta, a amante por ela conhecida. Ao chegar à residência de Ju, uma grande discussão se inicia e Rami acaba por apanhar e ser humilhada. Todavia, surge entre as duas uma certa cumplicidade, já que Julieta também está sendo traída por Tony e não sabe onde ele está. Rami, sempre por meio de discussões e brigas, descobre que há outras amantes: Luísa, Saly e Mauá Saulé. 
Nesse romance a prática da oralidade é visível em grande parte da narrativa, já que Paulina faz uso de frases curtas e rimas internas, trazendo à prosa um toque da poesia, ou melhor, um toque do canto das mais-velhas, canto este tomado para si pela narradora numa espécie de rito de passagem, no qual ela aprende com aquelas que cantam para mais tarde ensinar as outras esposas de Tony, pois, como ela diz, "nessa coisa de cantar, tenho as minhas raízes. Sou de um povo cantador" (CHIZIANE, 2004, p.17).

Como afirma Cândido Rafael Mendes da Silva (2008, p.40):

Os jogos articulados pelos saberes que a tradição oral, constantemente evocada e recriada por Paulina Chiziane, instaura no romance podem ser comparados àqueles estabelecidos pelo pacto firmado entre o público à volta da fogueira e o contador de estórias. Esse jogo é estabelecido pela atuação de um narrador principal, que "finge" ser um contador, e interage com as várias vozes com as quais dialoga ao longo da narrativa.

Para salientar esta narração-oral-poética de Chiziane, o trecho seguinte se mostra essencial: "[...] Como é que o Tony me despreza assim, se não tenho nada de errado em mim? Obedecer, sempre obedeci. As suas vontades sempre fiz. Dele sempre cuidei. Até as suas loucuras suportei" (CHIZIANE, 2004, p.16, grifos nossos). As rimas propõem, dessa forma, uma possibilidade de se guardar na memória as palavras da protagonista Rami, que também faz uso de técnicas que remetem a dramatizações, como no fragmento após o 
encontro com Julieta: "Sento-me na cadeira em segurança, e respiro fundo. Uf, mas que sova tão valente eu levei!" (CHIZIANE, 2004, p.29). Ou seja, o hibridismo no romance não se faz apenas por meio da linguagem, mas sim pela mescla de recursos de gêneros literários distintos: o drama e o romance.

Também se estabelecem como um processo da oralidade, no romance, as metáforas, que são articuladas por meio de digressões e redundâncias do discurso da narradora. "Fala-se em digressão sempre que a dinâmica da narrativa é interrompida para que o narrador formule asserções, comentários ou reflexões normalmente de teor genérico e transcendendo o concreto dos eventos relatados [...]" (REIS \& LOPES, 1988, p.237, grifos dos autores). Há, em Niketche, grandes metáforas que causam pausas na narrativa, algumas ocupando capítulos inteiros. Como afirma Leite (2012, p.102), "[...] a matéria narrativa concentrada, que poderia corresponder a um conto, [...] se alonga, por digressão e encaixe, em variantes, redundância, desmesura e variação". Ademais, essas metáforas se formulam como aspectos da escrita poética de Paulina, trazendo à tona, no romance estudado, pequenos pensamentos e conselhos da narradora, como no trecho a seguir:

Desperto-me na vã esperança de receber uma mão cheia de carinho, mas o sol deixou-me e partiu. 0 meu amor é fugidio como a sombra do sol.

A minha vida é um rio morto. [...] Sou um rio sem alma, não sei se a perdi e nem sei se alguma vez tive uma. Sou um ser perdido, encerrado na solidão mortal. (CHIZIANE, 2004, p. 20). 
Apesar de o uso ser menor, há trechos em que a narradora constrói um diálogo entre ela e seu público: "Vocês sabem o que dói ser tratada com altivez por quem vos rouba o marido?" (CHIZIANE, 2004, p.23, grifos nossos).

Além disso, existem quatro pequenas, mas extremamente importantes, passagens que marcam a presença de lendas, mitos e costumes em Niketche. Vale destacar que essas são as passagens que demonstram com mais vivacidade os aspectos supracitados, já que toda a narrativa está submergida em um processo de descrição da condição das mulheres moçambicanas.

A primeira trata de uma conversa de Rami com a sua tia Maria, anciã que viveu um relacionamento poligâmico em seus tempos de juventude:

- Era ainda espiga, os meus olhos ainda reflectiam sol e lua. Não conhecia ainda o significado da amargura. Éramos um grande rebanho de mulheres aguardando cobertura. [...]

[...]

- No nosso mundo não havia haréns - explica-me ela.

- Eram famílias verdadeiras, onde havia democracia social. Cada mulher tinha a sua casa, seus filhos, suas propriedades. Tínhamos o nosso órgão - assembleia das esposas do rei - onde discutíamos a divisão de trabalho, decidíamos quem iria cozinhar as papas matinais do soberano, quem ia preparar os banhos e esfregar os pés, cortar as unhas, massajar a coluna, aparar a barba, pentear-lhe o cabelo e outros cuidados. Participávamos na feitura da escala matrimonial de Sua Majestade, que consistia numa 
noite para cada uma, mas tudo igual, igualzinho. $E$ ele cumpria à risca. Ele tinha que dar um exemplo de Estado, um bom modelo de família. Se o rei cometesse a imprudência de dar primazia a uma muIher em especial, tinha que suportar as reuniões de crítica dos conselheiros e anciãos [...]. (CHIZIANE, 2004, p. 72-73).

É a partir desta conversa que Rami começa a questionar se a luta contra as esposas de seu marido se faz realmente necessária, já que fica evidente que na poligamia instituída há direitos das mulheres que devem ser respeitados. Torna-se perceptível o que Tania Macêdo e Vera Maquêa (2007) explicitam sobre as personagens femininas de Chiziane: mesmo que não existam dentro do universo literário dessa escritora moçambicana personagens femininas que rompam com a tradição e com o espaço no qual estão inseridas, existem "pequenos atos de rebeldia" (MACÊDO \& MAQUÊA, 2007, p. 83).

A segunda passagem advém de uma conversa de Rami com sua mãe sobre os costumes da sociedade moçambicana, como deixar para os homens comerem certas partes da galinha. Apesar de parecer algo banal, é pela voz da mãe da narradora que é possível conhecer um pouco mais sobre o modo como as mulheres moçambicanas são oprimidas e, muitas vezes, condenadas de forma indireta à morte por pequenos costumes:

Era domingo e a minha irmã preparou o jantar. Era galinha. Preparou a moela cuidadosamente e guardou numa tigela. Veio o gato e comeu. O marido re- 
gressou e perguntou: a moela? Ela explicou. Foi inútil. O homem sentiu-se desrespeitado e espancou-a selvaticamente. Volta para casa da tua mãe para ser educada, disse ele. Já! Ela estava tão agoniada que perdeu a noção do perigo e meteu-se em marcha na calada da noite. Eram cerca de dez quilómetros até ao lar paterno. Caiu nas garras do leopardo nas savanas distantes. Morreu na flor da idade por causa de uma imbecilidade. Morreu ela e ficou o gato. (CHIZIANE, 2004, p. 102).

Já na terceira e quarta passagens nota-se uma mise en abyme: a protagonista encontra-se enferma após inúmeras brigas com as amantes de seu marido e decide ir até um hospital. Chegando ao estabelecimento de saúde, ela se depara com um casal de idosos:

O marido está estendido numa maca que a mulher empurra, em passos de aflição. [...] O médico recebe-os com sorrisos e pergunta o que se passa. Ela diz tudo o que sabe, para ajudar o companheiro. De repente o velho ergue-se da maca rugindo furiosamente:

- Cala-te, mulher. Desde quando tens categoria para falar com um doutor? Nunca te autorizei a falar com homem nenhum. Estás a comportar-te como uma prostituta.

As palavras do velho despertam na mulher raivas sepultadas. Todas as mágoas afloram como um furacão, o sofrimento desta mulher foi uma constante, nas linhas do tempo. Ela reage e grita para o médico: 
- Velho rabugento! Suportei-lhe a vida inteira. Se não quer que eu fale, então que morra!

A velha abandona o companheiro estendido na maca. Dá passos em retaguarda. Percorre o corredor num voo como se respondesse ao chamamento da liberdade. O velho marido grita de raiva chamando por ela, mas esta não volta atrás. [...]

\section{Aquela cena me encanta, me choca e me espan- ta. [...] (CHIZIANE, 2004, p. 61.-62)}

Rami, ao final da narrativa, abandona Tony. Não há como negar que o fragmento acima trata-se de um presságio do futuro resguardado da narradora-protagonista, principalmente quando esta afirma que se sentiu encantada com a cena. O destino das personagens já se encontrava traçado no inconsciente de Rami.

E descrevendo o quarto trecho realçado nessa pesquisa, tem-se a presença direta de uma lenda dentro da narrativa contada por uma das tias de Tony:

- Era uma vez uma princesa. Nasceu da nobreza mas tinha o coração de pobreza. Às mulheres sempre se impôs a obrigação de obedecer aos homens. É a natureza. Esta princesa desobedecia ao pai e ao marido e só fazia o que queria. Quando o marido repreendia ela respondia. Quando Ihe espancava, retribuía. Quando cozinhava galinha, comia moelas e comia coxas, servia ao marido o que lhe apetecia. Quando a primeira filha fez um ano, o marido disse: vamos desmamar a menina e fazer outro filho. Ela disse que não. Queria que a filha mamasse dois 
anos como os rapazes, para crescer forte como ela. Recusava-se a servi-lo de joelhos e aparar-lhe os pentelhos. O marido, cansado da insubmissão, apelou à justiça do rei, pai dela. O rei, magoado, ordenou ao dragão para Ihe dar um castigo. Num dia de trovão, o dragão levou-a para o céu e a estampou na lua, para dar um exemplo de castigo ao mundo inteiro. Quando a lua cresce e incha, há uma mulher que se vê no meio da lua, de trouxa à cabeça e bebé nas costas. É Vuyazi, a princesa insubmissa estampada na lua. É a Vuyazi, estátua de sal, petrificada no alto dos céus, num inferno de gelo. E por isso que as mulheres do mundo inteiro, uma vez por mês, apodrecem o corpo em chagas e ficam impuras, choram lágrimas de sangue, castigadas pela insubmissão de Vuyazi. (CHIZIANE, 2004, p.157).

Tony convoca uma reunião às pressas na casa de sua mãe após a realização da dança niketche, o que ele considera como uma má conduta. A lenda, que não por acaso se inicia de forma tradicional, com um "era uma vez", serve, como já dito, a um propósito moralizante para as personagens femininas da história, principalmente a Rami, primeira-esposa responsável pelas demais. Entretanto, a lenda só serve para alimentar o sentimento de impotência da narradora diante das opressões sofridas pela mulher: "A ladainha cessa e, finalmente, o silêncio. Compreendi então que na alma das mulheres só existe morte, murmúrio de folhas caindo, gorjeio de rios invisíveis percorrendo o subterrâneo, detritos flutuando à deriva em águas lodosas" (CHIZIANE, 2004, p.158). No que tange à estrutura dessa lenda, além do início tradicional, são nítidos 
os recursos já explicitados, como frases curtas e rimas estratégicas (princesa/nobreza/pobreza/natureza), que embalam a melodia da fala.

A lenda também abre uma forma de leitura intertextual com a Bíblia: a princesa Vuyazi, desobediente aos mandamentos de seu marido, transforma-se em uma estátua de sal, assim como a mulher de Lot, do Antigo Testamento

Ao amanhecer, os anjos instavam com Lot, dizendo: 'Levanta-te, toma tua mulher e tuas duas filhas que estão em tua casa, para que não pereças também no castigo da cidade.'. [...] Quando já estavam fora, um dos anjos disse-Ihe: 'Salva-te, se queres conservar tua vida. Não olhes para trás, e não te detenhas em parte alguma da planície; mas foges para a montanha, senão perecerás'. [...] A mulher de Lot, tendo olhado para trás, transformou-se numa coluna de sal. (Gên. 19:15,17,26.)

O sal era um artefato utilizado em cerimônias fúnebres para purificar lugares e/ou pessoas que fossem consideradas impuras. Desse modo, pode-se entender que tanto a princesa Vuyazi quanto a mulher de Lot eram consideradas contaminadas por algo que não deveria se propagar em suas comunidades: a insubordinação aos preceitos masculinos custaram-lhe a vida, convertendo-se em exemplos para as outras mulheres.

Doris Wieser (2014), que estuda, por meio da política e da literatura, a construção identitária portuguesa e moçambicana, teve a oportunidade de entrevistar Chiziane durante uma viagem a Moçambique e a questionou sobre o sincretis- 
mo religioso presente no país. A escritora afirmou, então, que se tornou comum nas culturas bantu ${ }^{2}$ a absorção de outras perspectivas religiosas, devido ao processo de colonização. Ademais, é perceptível a importância dessa associação de culturas dentro da narrativa de Paulina Chiziane:

Aqui o conhecimento da história do cristianismo e do islamismo é importante. Se olharmos para a história da Bíblia sagrada, é muito bonita. Eu gosto de ler a Bíblia no sentido da busca de diferenças. Quando abrimos o Génesis e o Éxodo, a primeira referência territorial é em África: Egito. Depois vêm Abraão e Moisés. São as três grandes figuras de que eu gosto. Abraão chega com a sua mulher, que era estéril, no Egito e recebe como prenda do faraó uma escrava egípcia com quem vai ter o filho Ismael, que é considerado o pai da nação árabe. Então a história do mundo árabe começa em África. Depois Moisés, que é criado como um príncipe pela filha do faraó, aprende tudo sobre conhecimento, leitura, escrita, etc., e tem a grande revelação divina no monte Sinai que fica no Egito, escreve os Dez Mandamentos no Egito e parte para a terra prometida. Os Dez Mandamentos da lei de Deus foram escritos em solo africano por um indivíduo nascido e criado em África. O cristianismo e o islamismo têm África como berço. Mas, quando o europeu pega na história, inventa outra para apagar as origens desta grande coisa que eles consideram religião e que depois deu origem a tantos outros desenvolvimentos. Querem excluir África quando não se pode excluir. (WIRSE, 2014).

2 Grupo etnolinguístico que se estende pela África subsaariana. 
Ainda no que tange aos quatro trechos evidenciados, vale ressaltar que o tempo verbal da narração muda: o presente, o momento no qual se encontram as personagens, é deixado de lado para que um tempo antigo, ou seja, tradicional, abra passagem para ensinamentos. Todavia, essa narração não ocorre em pretérito perfeito, mas sim no pretérito imperfeito. Tal constatação se faz importante, visto que esse novo tempo verbal traz à narrativa a característica de uma ação durativa, não limitada no tempo. A tradição está sempre presente, conforme declara Ana Mafalda Leite (2013): "As histórias ilustram tal saber, efabulam a tradição, percorrem uma temporalidade específica, uma vez que se trata da reapropriação de uma voz e conhecimento seculares, retomada e resposta em atitude griótica $^{3}$ de pedagogia crítica" (LEITE, 2013, p.79). Há uma voz narrativa trans-histórica que acompanha "tempos imemoriais" e que é trazida pela narradora e pelas outras personagens femininas (MACÊDO \& MAQUÊA, 2007, p.79).

Desse modo, é esperado que a retomada de um passado mítico ocorra na narrativa graças à presença de um provérbio zambeziano que abre o romance: "Mulher é terra. Sem semear, sem regar, nada produz".

Ora a inserção do provérbio no enunciado confirma o sentido do texto, realizando uma espécie de registro da uma "fala comum" que é reativada no texto para confirmar a própria fala do narrador: ora a sua cita-

3 Termo de origem francesa (griot), que designa "[...] uma série de funções no contexto das sociedades africanas de tradição oral. Os griots teriam assumido uma posição de destaque, pois Ihes cabia a função de transmitir a tradição histórica: eram os cronistas, genealogistas, arautos, aqueles que dominavam a palavra, sendo, por vezes, excelentes poetas; mais tarde passaram também a ser músicos e a percorrer grandes distâncias, visitando povoações onde tocavam e falavam do passado" (LIMA \& COSTA, 2014, p.223, grifos dos autores). 
ção exerce uma função desconstrutiva e irônica do conteúdo posto. No caso da confirmação, o provérbio poderia aturar como elemento de ligação entre o texto e o extratexto. Como tal, o provérbio implicaria uma instituição social, a qual, por sua vez, implica uma situação de enunciação convencionalmente definida: a função pragmática do provérbio. Funcionaria como conector, referindo-se expressamente ao texto e ao intertexto, integrando de modo manifesto um e outro. (MOREIRA, 2005, p.114-115).

Por fim, é interessante notar na obra de Paulina a questão do narrador abordada por Walter Benjamin (1987), em seu ensaio "O narrador", já que o crítico inicia o texto afirmando que "[...] entre as narrativas escritas, as melhores são as que menos se distinguem das histórias orais contadas pelos inúmeros narradores anônimos" (BENJAMIN, 1987, p.198). Desse modo, os narradores, segundo Benjamin, dividem-se em dois grupos: o narrador dito marinheiro comerciante, aquele que vem de longe e traz consigo novas histórias; e o narrador dito agricultor sedentário, que mesmo não viajando, conhece muito bem as histórias e tradições do local em que mora. Pode-se dizer que, além de trabalhar muito bem a questão da oralidade, Paulina Chiziane faz parte dos dois grupos de narradores explanados pelo crítico graças ao trabalho de assistente social em Moçambique:

As suas viagens pelo país, a trabalho, Ihe permitiram recriar em ficção as dificuldades do dia a dia das mulheres moçambicanas. Ela consegue, através da sua escrita, (re)construir, (re)transformar e/ 
ou trazer à tona o universo doloroso e silenciado das mulheres. A escrita de Paulina Chiziane é como um palco em que as mulheres aparecem gritando as suas vontades de querer mudar o cotidiano sofrido. (ROBERT, 2010, p.52).

E nas palavras da própria autora: "Na minha obra, ficção e realidade caminham de mãos dadas. Escrevo a realidade do meu mundo com todos os seus prazeres, mágoas, tristezas e frustrações. Da realidade vivida parto para uma realidade imaginária [...]" (LABAN, 1998, p.973-974).

É por causa dessa realidade moçambicana presente nos livros de Chiziane que se pode perceber a subversão dos conhecimentos ocidentais europeus: "Olhei-a com surpresa. De repente lembro-me de uma frase famosa - ninguém nasce mulher, torna-se mulher. Onde terei eu ouvido esta frase?" (CHIZIANE, 2004, p.37, grifos em itálico da autora, grifos em negrito nossos). A alteração do significado original da frase de Simone de Beauvoir acontece graças ao processo de se tornar mulher, empregado pela narradora-protagonista. Nesse trecho, Rami começa a ter aulas de iniciação sexual com uma famosa conselheira amorosa, para que, assim, consiga reconquistar seu marido. Em algumas partes de Moçambique é comum a prática dos chamados ritos de passagem: para que um indivíduo possa continuar se desenvolvendo espiritualmente, e assim, em comunhão com a sociedade que o cerca, alguns rituais devem ser feitos em idades específicas, geralmente correspondendo a uma passagem da infância para a vida adulta, da vida adulta para a velhice e, por último, da velhice 
para a ancestralidade, quando o ser humano morre e retorna ao ciclo da vida. Rami, entretanto, foi criada conforme as leis da religião católica. Dessa forma, ela nunca passou por quaisquer rituais que a ensinassem a se tornar uma mulher.

\section{- São assim tão importantes esses ritos?}

- Sem eles, és mais leve que o vento. És aquele que viaja para longe, sem viajar antes para dentro de si próprio. Não te podes casar, ninguém te aceita. Se te aceita, logo depois te abandona. Não podes participar num funeral, muito menos aproximar-te de um cadáver porque não tens maturidade. Nem podes assistir a um parto. Não podes tratar dos assuntos de um casamento. Porque és impura. Porque não és nada, eterna criança. (CHIZIANE, 2004, p.40, grifos nossos).

Em outro ponto da narrativa, quando as esposas de Tony partem em busca de uma nova mulher para ele, a escolhida, apesar de ser muito jovem, já concluiu os ritos necessários para a vida adulta:

- És ainda criança.

- Tenho dezoito anos. Donzelei aos quinze. Sei lavar roupa e lavar a loiça. Não sei cozinhar bem, posso aprender, mas sei o mais importante: tenho escamas e tenho lulas ${ }^{4}$. Aprendi como se faz amor, nos ritos de iniciação.

4 Ao contrário do que acontece em algumas regiões do continente africano, em Moçambique é incentivado o alongamento do clitóris para que a mulher sinta mais prazer. Assim, ter escamas e lulas são processos de transformação pelos quais o órgão genital feminino passa. 
- Donzelar?

- Sim. Donzelar é celebrar os ritos de iniciação. (CHIZIANE, 2004, p. 322).

Fica evidente, desse modo, como a escrita e a oralidade contribuem para uma deturpação do cânone euroupeu-ocidental efetuado por Paulina em Niketche: uma história de poligamia.

\section{REFERÊNCIAS BIBLIOGRÁFICAS}

BENJAMIN, Walter. O narrador: considerações sobre a obra de Nikolai Leskov. In: Magia e técnica, arte e política. 7.ed. Trad. Sergio Paulo Rouanet. São Paulo: Brasiliense, 1994. p. 197-221.

BÍBLIA. Bíblia Sagrada Ave-Maria. São Paulo: Ave-Maria, 2002.

CHIZIANE, Paulina. [Testemunho] Eu, mulher... por uma visão do mundo. Revista Abril, Niterói, v. 5, n. 10, p.199-205, 2013. Disponível em: http://www.revistaabril.uff.br/index.php/revistaabril/article/view/114/73. Acesso em: 13 jul. 2017.

. Niketche: uma história de poligamia. Lisboa: Caminho, 2004.

HAMPATÉ BÂ, Amadou. A tradição viva. In: KI-ZERBO, Joseph. (org.). História geral da África I: Metodologia e pré-história da África. 2.ed.rev. Brasília: UNESCO, 2010. 
LEITE, Ana Mafalda. Oralidades \& escritas pós-coloniais: estudos sobre literaturas africanas. Rio de Janeiro: EdUERJ, 2012.

LIMA, Mestre Alcides de; COSTA, Ana Carolina Francischette da. Dos griots aos Griôs: a importância da oralidade para as tradições de matrizes africanas e indígenas no Brasil. Revista Diversitas, São Paulo, n. 3, p.216-245, set 2014/mar 2015. Disponível em: http://diversitas.fflch.usp.br/node/3661. Acesso em: 14 jul. 2017.

MACÊDO, Tania., MAQUÊA, Vera. Literaturas de língua portuguesa: marcos e marcas - Moçambique. São Paulo: Arte \& Ciência, 2007.

MANJATE, Rogério. "Paulina Chiziane - Ser escritora é uma ousadia!!!". Maderazinco - Revista Literária Moçambicana, Maputo, 1 set. 2004.

MATA, Inocência. Mulheres de África no espaço da escrita: a inscrição da mulher na sua diferença. In: MATTA, Inocência; PADILHA, Laura Cavalcante. (org). A mulher em África: Vozes de uma margem sempre presente. Lisboa: Edições Colibri, 2007.

MOREIRA, Terezinha Taborda. O vão da voz: a metamorfose do narrador na ficção moçambicana. Belo Horizonte: Edições Horta Grande Ltda, 2005.

REIS, Carlos, LOPES, Ana Cristina. Dicionário de Teoria da Narrativa. São Paulo: Editora Ática, 1988. 
ROBERT, Badou Koffi. A consciência da subalternidade: trajetória da personagem Rami em Niketche de Paulina Chiziane. 2010. 105 f. Dissertação (Mestrado em Estudos Comparados de Literaturas de Língua Portuguesa) - Faculdade de Filosofia, Letras e Ciências Humanas, Universidade de São Paulo, São Paulo.

SALGADO, Maria Teresa. Um olhar em direção à narrativa contemporânea moçambicana. Scripta, Belo Horizonte, v. 8, n. 15, p.297-308, 2014. Disponível em: http://www.ich.pucminas.br/cespuc/Revistas_Scripta/Scripta15/Conteudo/N15_ Parte03_art07.pdf. Acesso em: 04 dez. 2016.

SILVA, Cândido Rafael Mendes da. Xibonini: a metáfora dos espelhos em Niketche, de Paulina Chiziane. 2008. 118 f. Dissertação (Mestrado em Letras Vernáculas - Literaturas Portuguesa e Africanas) - Universidade Federal do Rio de Janeiro, Rio de Janeiro

SILVA, Rejane Vecchia Rocha e; SOUZA, Ubiratã Roberto Bueno de. Literatura moçambicana e oralidade: uma postura crítica e uma fundamentação teórica. Scripta, Belo Horizonte, v. 19, n. 37, p.97-120, 2015. Disponível em: http://periodicos.pucminas.br/index.php/scripta/article/view/P.2358-3428. 2015v19n37p97/9663. Acesso em: 06 dez. 2016.

SPIVAK, Gayatri Chakravorty. Pode o subalterno falar? Trad. Sandra Regina Goulart Almeida; Marcos Pereira Feitosa; André Pereira Feitosa. Belo Horizonte: Editora UFMG, 2014. 
WIESER, Doris. "Os anjos de Deus são brancos até hoje, entrevista a Paulina Chiziane". Buala, 26 nov. 2014. Disponível em: http://www.buala.org/pt/cara-a-cara/os-anjos-de-deus-sao-brancos-ate-hoje-entrevista-a-paulina-chiziane. Acesso em: 13 jul. 2017.

Submissão: 28/07/2017

Aceite: 29/10/2017 